\title{
CONSTRUÇÃO COLETIVA DO PROJETO POLÍTICO PEDAGÓGICO EM UMA ESCOLA PÚBLICA MUNICIPAL: DESAFIOS E POSSIBILIDADES REAIS.
}

Thays Ribeiro Guedes, Alana Silva Moreira, Vanda Moreira Machado Lima.

Universidade Estadual Paulista - UNESP, Licenciatura em Pedagogia, Presidente Prudente, SP. E-mail: thaysguedes170@gmail.com.

Agência de fomento: PROGRAD/Núcleo de Ensino

\section{RESUMO}

A construção do Projeto Político Pedagógico (PPP) de uma escola é sempre um grande desafio a todos os profissionais da educação. Este artigo visa refletir sobre os desafios e as possibilidades reais de construção coletiva do PPP de uma escola pública municipal. A pesquisa se insere na abordagem qualitativa, e utilizou como instrumentos na coleta de dados a pesquisa bibliográfica, a observação participante, o registro reflexivo e o questionário. Para categorização e análise das questões abertas recorremos à técnica de análise de conteúdo (FRANCO, 2008), na qual elaboramse as categorias a partir da análise da resposta escrita dos sujeitos. Constatamos que o principal desafio foca-se em articular as diversas opiniões dos membros da equipe escolar sobre um mesmo tema, contudo, com a discussão em grupos, subsidiada pela opinião individual e discussão no coletivo, foi possível a escola parceira superar essa dificuldade.

Palavras-chave: Gestão Democrática, Trabalho Coletivo, Projeto Político Pedagógico, Escola Pública Municipal, Anos iniciais do ensino fundamental.

\section{COLLECTIVE CONSTRUCTION OF THE PEDAGOGIC POLITICAL PROJECT IN A MUNICIPAL PUBLIC SCHOOL: REFLECTION ON SCHOOL IDENTITY.}

\begin{abstract}
The construction of Pedagogic political project (PPP) a school is always a great challenge to all education professionals. This article aims to reflect on the challenges and possibilities of collective construction of PPP of a municipal public school. The research in the qualitative approach, and used as instruments in the collection of data to bibliographical research, participant observation, reflective and the questionnaire. For categorization and analysis of open questions we used the technique of content analysis (FR, 2008), in which elaborate the categories from the analysis of the written reply of the subjects. We found that the main challenge focuses on articulating the different opinions of the members of the school team on the same theme, however, with discussion groups, subsidized by individual opinion and discussion in the collective, the partner school through this difficulty.
\end{abstract}

Keywords: Democratic management, collective work, Pedagogical political project, Municipal Public School, early years of elementary school. 


\section{INTRODUÇÃO}

Desde 2011 estabelecemos uma parceria entre a Universidade e uma escola pública municipal de Ensino Fundamental vinculada à Secretaria Municipal de Educação de Presidente Prudente, SP, que vem proporcionando momentos de reflexões e experiências únicas para formação inicial dos alunos do curso de Pedagogia. No ano de 2015 iniciamos com a proposta de elaboração de uma ação de formação continuada para os professores a partir das necessidades formativas dos docentes e da equipe gestora da escola parceira, a ação de formação continuada focou os professores do 1 을 ano do ciclo I do ensino fundamental. Ao avaliarmos a ação de formação continuada desenvolvida decidimos que em 2016 o foco continuaria sendo os professores do 10 ano, visto que os docentes que são novos na escola.

O contato direto com o cotidiano da escola, propiciado pelo financiamento do Programa Projeto Núcleo de Ensino da PROGRAD/UNESP, nos possibilitou vivenciar uma série de experiências enriquecedoras, sendo uma delas a construção coletiva do Projeto Político Pedagógico (PPP).

Diante dessas considerações este artigo visa refletir sobre os desafios e as possibilidades reais de construção coletiva do PPP de uma escola pública municipal.

\section{METODOLOGIA}

Para subsidiar nossas ações na escola parceira optamos pelos princípios da pesquisa qualitativa, que tem como principal preocupação a compreensão dos fenômenos sociais, crenças e concepções de sujeitos investigados e a interpretação que estes atribuem a um determinado fenômeno. Utilizamos como instrumentos na coleta de dados a pesquisa bibliográfica, a observação participante, o registro reflexivo e o questionário. Para categorização e análise das questões abertas recorremos à técnica de análise de conteúdo (FRANCO, 2008), na qual elaboramse as categorias a partir da análise da resposta escrita dos sujeitos.

Com a pesquisa bibliográfica possibilita-se que o grupo da universidade (bolsistas e coordenadora) construa o suporte teórico que fundamenta nossas ações na escola parceira, junto aos professores do 10 ano do ensino fundamental (EF). A observação participante permite que o pesquisador, conforme os apontamentos de Reys e Monteiro (2010, p. 19), se envolva "com os sujeitos em seu cotidiano, tentando sentir o que significa estar naquela situação".

O registro reflexivo das observações é elaborado individualmente, debatido em nosso grupo de pesquisa, sintetizado, apresentado e discutido junto à equipe gestora e aos professores polivalentes do 10 ano da escola parceira. O questionário foi aplicado a todos os profissionais da escola presentes na reunião de planejamento, num total de 23 sujeitos. Para categorização e análise das questões abertas recorremos à técnica de análise de conteúdo (FRANCO, 2008), na qual elaboram-se as categorias a partir da análise da resposta escrita dos sujeitos.

Esta pesquisa foi aprovada pelo Comitê de Ética em Pesquisa (CEP) da FCT/UNESP com número 27133714.3.0000.5402.

\section{RESULTADOS}

Como resultados apresentamos dois aspectos, inicialmente a descrição da reunião de planejamento e posteriormente os dados dos questionários analisados.

\section{DESCRIÇÃO DA REUNIÃO DE PLANEJAMENTO}

Em maio de 2016 tivemos a oportunidade de vivenciar um momento único para nossa formação inicial e atuação como futuras professoras e gestoras escolares, uma reunião de construção do PPP em uma escola pública municipal.

O ano de 2016 iniciou-se com a proposta de reelaboração de todos os PPP das escolas públicas municipais. Na escola pesquisada, a equipe gestora optou por construir gradativamente seu PPP com o envolvimento de todos da equipe escolar. 
Num primeiro momento, na Semana de Planejamento de Escolar de 2016, ao qual não acompanhamos por não termos iniciado a pesquisa ainda. E um segundo momento, que se constituiu em um encontro com toda equipe escolar, equipe gestora, professores e funcionários no dia 08 de abril de 2016, das $7 \mathrm{~h}$ às $17 \mathrm{~h}$, ao qual participamos.

Inicialmente a equipe gestora organizou uma dinâmica, que se constitui em dar a cada pessoa presente no encontro uma peça de um quebra cabeça. Ao montar o quebra cabeça foi possível identificar a seguinte frase: "nenhum de nós é tão bom quanto todos nós juntos". Em seguida, a diretora fez uma inferência ao Projeto Político Pedagógico, ressaltando a importância da contribuição, mesmo que singela, de todos, para sua construção democrática e efetiva.

Posteriormente, contamos com a contribuição de uma professora da universidade que apresentou de modo sucinto o significado do PPP e a importância da construção desse documento ocorrer de modo coletivo.

O Projeto Politico Pedagógico é um documento que propõe uma direção politica e pedagógica ao trabalho escolar, formula metas, prevê ações, institui procedimentos e instrumentos de ação. (LIBÂNEO; OLIVEIRA; TOSCHI, 2012, p. 470).

Com o intuito de envolver todos na redação do PPP da escola, solicitou-se que cada presente respondesse a seguinte indagação: "Na construção coletiva do Projeto Político Pedagógico (2016/2018) da nossa escola, a sua opinião e a sua atitude são fundamentais". Diante disso, escreva qual identidade a nossa escola quer construir sobre: a) "Criança (06 aos 10 anos), b) Escola (local), c) Processo de Ensino-Aprendizagem (Professor), d) Ações Educativas (Equipe Gestora e Equipe de Apoio)".

Depois do registro individual, a equipe gestora organizou a formação de grupos para discussão e síntese final. Os grupos deveriam ter pessoas de diferentes segmentos da escola, registrar a opinião e, posteriormente apresentar o resultado do trabalho do grupo aos demais membros da equipe escolar.

Todo esse material resultará em parte da redação do PPP da escola pesquisada, que retornará após escrita para novos debates, reflexões e discussões na equipe escolar.

APRESENTAÇÃO DOS DADOS DO QUESTIONÁRIO

Apresentaremos os dados tabulados de duas questões. A primeira referente ao perfil do aluno, e a segunda referente à construção do perfil da escola.

Ao indagarmos os 23 sujeitos sobre que criança a escola deve formar, construímos seis categorias, com as seguintes respostas:

$-34,7 \%$ (8 respostas) apontam que a criança deve "respeitar princípios básicos de convivência social, emitir suas opiniões e respeitar as opiniões dos outros", 39,0\% dos respondentes apontaram a formação da criança "cidadã, critica e reflexiva, consciente de seus direitos e deveres, que interpreta a sociedade";

- 34,7\% (8 respostas) destacaram a formação da criança que "cumpre seus deveres como estudante (realiza atividades de sala e casa, aprenda a ler, interpretar, escrever e operar com números, compreenda e produza textos), respeite funcionários e as normas da escola;

- 26,08\% (6 respostas) afirmam que a criança deve ser "ativa, crítica, participativa, autônoma, respeitosa, iniciativa, segura, social";

E também, tivemos 3 respostas que apontaram a criança como "alguém que desenvolve suas habilidades e potencialidades para resolver situações problemas na vida acadêmica e social, articulando-os a seu dia-a-dia; apenas dois sujeitos apontaram a criança como um sujeito em desenvolvimento.

Em relação ao perfil de escola que desejam construir obtivemos oito categorias, com total de 55 respostas que apresentamos a seguir:

- 69,56\% (16 respostas) gostariam que a "escola propiciasse condições para um processo de ensino e aprendizagem do aluno com qualidade". 
"Instituição de ensino que seja capaz de atender com excelência todos os alunos [...]" (Sujeito 3).

- 43,48\% (10 respostas) querem uma escola que "realize um trabalho coletivo, com uma equipe articulada que contribua para melhores resultados na instituição escolar".

"Escola unida [...] onde cada um é ciente do seu papel e colaborativo com o papel do outro" (Sujeito 11).

- 30,43\% (7 respostas) afirmaram que a escola deveria "atender as diversidades respeitando as diferenças e suprindo as peculiaridades igualitariamente".

"Que a escola atenda os alunos especiais, os alunos indisciplinados e com baixa aprendizagem [...]" (Sujeito 12 ).

- 26,08\% (6 respostas) desejavam que a escola "oferecesse uma diversidade de recursos e matérias para auxiliar no processo de ensino".

"Que a escola diversidade de estratégias de atividades com matérias necessárias para atender todos os alunos [...]" (Sujeito 5).

- 21,73\% (5 respostas) afirmaram que a escola "deveria preparar o aluno fornecendo conhecimento suficiente para o exercício da cidadania plena".

"Que possibilite a esse aluno conviver em sociedade de modo autônomo e critico [...]" (Sujeito 1).

- 21,73\% (5 respostas) preferem uma escola "com regras para o bom funcionamento escolar".

“[...] regras bem estabelecidas e cumpridas no dia a dia" (Sujeito 15).

- 13,04\% (3 respostas) ressaltam a importância de "um clima organizacional positivo".

"Um ambiente agradável, organizado, com uma equipe bem articulada, na qual cada um tenha consciência de seu papel e o desempenhe em prol do aluno, buscando desenvolvê-lo intelectualmente e socialmente [...]" (Sujeito 10$)$.

Ainda obtivemos 3 respondentes que apontaram a importância da "analise de porcentagem de desempenho na escola".

\section{DISCUSSÃO}

A construção de uma escola pública dos anos iniciais democrática, inclusiva, crítica, reflexiva e de qualidade para todos é ainda um enorme desafio, mas a valorização da gestão democrática, como a construção coletiva do PPP pode ser um primeiro passo para essa escola se tornar real. A Gestão democrática vem sendo objeto de reflexões, debates e indagações em pesquisas de âmbito educacional, além de ser princípio e obrigatório nas escolas púbicas segundo nossas legislações, como a Constituição Federal de 1988 (CF-88) e a Lei de Diretrizes e Bases da Educação Nacional n. 9394-96 (LDB-96), (CURY, 2014).

Vieira e Vidal $(2015$, p. 23) declaram que a gestão democrática é detalhada no:

Art. 14. Os sistemas de ensino definirão as normas da gestão democrática do ensino público na educação básica, de acordo com suas peculiaridades e conforme os seguintes princípios: 
I- participação dos profissionais da educação na elaboração do projeto pedagógico da escola;

II- participação das comunidades escolar e local em conselhos escolares ou equivalentes.

Em relação ao Plano Nacional de Educação, Lei no 13.005/2014 (BRASIL, 2014), a gestão democrática se faz presente em duas metas. A meta 7 trata da qualidade da educação básica em todas as etapas e modalidades. Já a meta 19 tem foco específico assegurar condições, no prazo de 2 (dois) anos, para a efetivação da gestão democrática da educação.

Segundo Libâneo; Oliveira; Toshi (2014), a organização e os processos de gestão assumem diferentes modalidades conforme a concepção das finalidades sociais e políticas da educação em relação a sociedade e a formação dos alunos, sendo elas a concepção técnico-científica, onde o tecnicismo prevalece juntamente com a gestão centralizada; a concepção interpretativa, onde as interações e a interpretação das pessoas são fundamentais; e a concepção democráticoparticipativa, que se baseia na relação orgânica entre direção e participação dos membros da equipe.

Faz-se essencial que nossas escolas públicas possam elaborar ações que possibilitem discussões, reflexões, que tornem a escola espaço de formação para todos. Afinal, como afirma Libâneo (2013, p. 32), a escola precisa ser compreendida como "um espaço educativo, uma comunidade de aprendizagem constituída pelos seus componentes, um lugar em que os profissionais podem decidir sobre seu trabalho e aprender mais sobre a sua profissão".

A equipe gestora das escolas precisa compreender uma de suas funções que é administrar interesses pessoais e coletivos, peculiaridades culturais, exigências universais, relações humanas, estabelecer formas e práticas participativas nos processos administrativos, entre outros. Afinal

[...] para desenvolver práticas gestoras democráticas, participativas, colaborativas no dia a dia da escola, é preciso envolver os sujeitos política e pedagogicamente na proposta indicada no PPP da escola. Para tanto, é fundamental que se aprimorem as concepções e o debate sobre o que se entende por democracia e por gestão democrática, compreendendo que em tais processos deve prevalecer a corresponsabilidade e a coparticipação. (SARTORI, 2015, p. 47).

Como afirma Paro (2007), a visão que temos sobre a escola pública assume diferentes funções, como: promotora social, preparadora para o mercado de trabalho, para a continuação dos estudos, ou até mesmo um depósito de crianças.

O trabalho da escola além de educar, é formar cidadãos responsáveis que defendam e conheçam seus direitos e, também cumpram com seus deveres. A escola deve atuar como uma instituição que prepara para a consciência política e a cidadania, não apenas na promoção de conteúdos. Acreditamos que atividades coletivas como a desenvolvida na escola parceira contribui para a construção de uma escola como espaço de formação aos seus profissionais e também contribui significativamente para a melhoria do ensino.

\section{CONCLUSÃO}

Participar desse momento propiciou-nos conhecer na prática um pouco mais sobre a Gestão Democrática e a construção do PPP. Percebemos como principal desafio o ouvir e articular opiniões diferentes sobre a criança, a escola, o professor, a equipe de apoio e a equipe gestora, refletindo sobre o que temos e o que precisamos construir para atingir um ensino de qualidade. 
Contudo ouvir os diferentes profissionais que atuam na escola foi enriquecedor, pois debatemos com diversos professores sobre o seu papel e o da escola. Os funcionários e gestores também abordaram aspectos sobre o seu papel na escola e seus desafios.

É primordial que cursos de formação de professores garantam o debate e a formação do futuro professor e gestor que, visto que apesar de haver grande discussão sobre a Gestão democrática "ainda é incipiente a produção acadêmica sobre estágio curricular na formação das equipes gestoras das escolas de educação básica" (PRADO, 2012, p. 38).

Apesar de ser uma construção ainda em andamento, é perceptível o esforço da equipe gestora para a efetivação da Gestão Democrática, visto que essa gestão,

[...] começa na elaboração do projeto pedagógico. Se o estabelecimento deve elaborá-lo, ele não pode fazê-lo sem a participação dos profissionais da educação. Logo, a gestão do projeto pedagógico é tarefa coletiva do corpo docente e se volta para a obtenção de outro princípio constitucional que é a garantia do padrão de qualidade, posto no inciso VII do art. 206. (CURY, 2014, p. 17).

\section{REFERÊNCIAS}

BRASIL. Constituição da República Federativa do Brasil. Brasília: Senado Federal, 1988.

BRASIL. Lei n. 9.394, de 20 de dezembro de 1996. Estabelece as diretrizes e bases da educação nacional. Diário Oficial da União, 23 dez. 1996. Seção 1, p.207.

BRASIL. Lei n. 13.005/2014, de 25 de Junho de 2014. Aprova o Plano Nacional de Educação - PNE e dá outras providências. Brasília: Câmara dos Deputados, Edições Câmara, 2014.

CURY, C. R. J. Gestão democrática dos sistemas públicos de ensino. In: OLIVEIRA, M. A. M. (Org) Gestão Educacional: novos olhares. Novas abordagens. 10. Ed. Petrópolis, RJ: Editora Vozes, 2014, p. 15-21.

FRANCO, M. L. P. Análise de conteúdo. 3. ed. Brasília: Líber Livro, 2008.

LIBÂNEO, J C; OLIVEIRA, J F; TOSCHI, M S. Educação Escolar: políticas, estrutura e organização. São Paulo: Cortez, 2012, p. 470-543.

LIBÂNEO, J. C. A escola como organização de trabalho e lugar de aprendizagem do professor. In__. Organização e Gestão da Escola: teoria e prática. 6. ed. rev. e amp. São Paulo: Heccus, 2013, p. 29-40.

PARO, V. O papel da escola. In: PARO, V. Qualidade do ensino: a contribuição dos pais. São Paulo: Xamã, 2007. p. 51-64.

REYS, C. R.; MONTEIRO, H. M. Olhando e observando. In: REYS, C. R.; MONTEIRO, H. M. Um olhar crítico-reflexivo diante da realidade educacional. São Carlos: EdUFSCar, 2010, P. 11-29

SARTORI, J. O Ensino em Gestão Escolar: desafios à gestão dos processos pedagógicos. In: LOSS, A. S; SARTORI, J.; PIEROZAN, S.S.H. (Orgs) Estágio Supervisionado em Pedagogia: concepções e práticas. 1ed. Curitiba: Appris, 2015. p. 39-48. 
VIEIRA, S. L.; VIDAL, E. M. Gestão democrática da escola no Brasil: desafios à implementação de um novo modelo. Revista Iberoamericana de educación, 2015, Issue 67, p.19-38. 